\title{
Projected climate changes in four different regions in Colombia
}

\author{
Oscar D. Molina* (1D) and Christian Bernhofer
}

\begin{abstract}
Background: Considering the lack of research over this region the Statistical Downscaling Model (SDSM) was used as a tool for downscaling meteorological data statistically over four representative regions in the eastern side of Colombia. Data from the two Global Climate Models CanESM2 and IPSL-CM5A-MR, which are part of the CMIP5-project have been used to project future maximum and minimum temperature, precipitation and relative humidity for the periods 2021-2050 and 2071-2100. For both models, the Representative Concentration Pathways RCP2.6 and RCP8.5 were considered, representing two different possible future emission trajectories and radiative forcings. Predictor variables from the National Centre for Environmental Prediction (NCEP-DOE 2) reanalysis dataset, together with analyzed correlation coefficient (R) and root mean square error (RMSE) were used as performance indicators during the calibration and validation process.

Results: Results indicate that Maximum and minimum temperature is projected to increase for both Global Climate Models and both Representative Concentration Pathways; relative humidity shows a decreasing trend for all scenarios and all regions; and precipitation shows a slight decrease over three regions and an increase over the warmest region. As expected, the results of the simulation for the period 2071-2100 show a more drastic change when compared to the baseline period of observations.

Conclusions: The SDSM model proves to be efficient in the downscaling of maximum/minimum temperature as well as relative humidity over the studied regions; while showing a lower performance for precipitation, agreeing with the results for other statistical downscaling studies. The results of the projections offer good information for the evaluation of possible future-case scenarios and decision-making management.
\end{abstract}

Keywords: Downscaling, Colombia, SDSM, Climate change

\section{Background}

Global climate change is one of the greatest concerns of humanity given the great impact it has for the future sustainability of socioeconomic and environmental development. According to the Intergovernmental Panel on Climate Change (IPCC), a climate change scenario is a climate response under the assumption of emissions of greenhouse gases (GHG) into the atmosphere; therefore, depending on the scenario analyzed, a different change in meteorological patterns is allowed, induced by a greater or lesser emission of gases throughout the twenty-first century (Jones et al. 2004).

*Correspondence: oscar_david.molina_rincon1@tu-dresden.de Institute of Environmental Sciences, University TU Dresden, Dresden, Germany
In order to estimate the effect that greenhouse gas emissions have on the global climate, Global Climate Models (GCMs) have been used for this purpose. GCMs describe physical elements and important processes in the atmosphere, ocean, and soil that occur within the climate system. The main disadvantage of GCMs is their spatial resolution, which is adequate for a few $100 \mathrm{~km}$; thus, they do not capture regional and local meteorological details. In order to study the impacts of climate change on the regional level, it is necessary to predict changes on much finer scales. One of the best known techniques to do this is through the use of Regional Climate Models (RCMs). The RCM is an atmospheric physics-based model to which boundary conditions are provided with the output of a GCM. Downscaling technique is the method for creating local climate scenarios 
from GCM climate scenarios, and they are broadly classified into two categories: dynamic downscaling and statistical downscaling. Statistical downscaling methods construct statistical relationships between the large scale GCM outputs (predictors) and the catchment scale climate variables (predictands). The basic advantage of statistical downscaling is that it is computationally less demanding compared to dynamic downscaling. Wilby et al. (2002) and other authors have studied downscaling techniques and stated that by using this approach, GCM outputs can be changed into surface variables in the scale of a basin or smaller areas under study. According to Wilby and Wigley (2000), statistical downscaling is based on the assumption that the predictor-predictand relationships are valid under future climatic conditions, and predictor variables and their changes are well characterized by GCMs.

Worldwide, Colombia is one of the richest countries in water resources. Its climate presents varied conditions with the coldest weather being located on its snowy mountains and the warmest at sea level. Precipitation is governed by the double crossing of the Inter Tropical Convergence Zone (ITCZ); however, there is also the influence of trade winds and climatic variability events such as El Niño-La Niña, intra-seasonal Madden-Julian oscillation (MJO), among others. Regional physicalgeographic factors such as orography also play a role (IDEAM 2005). These patterns of circulation and according to IPCC could be altered by the emission of greenhouse gases. Colombia is a country with relatively low industrial development, for this reason, the quantity of greenhouse gas emissions is not in a proportion that they have become a decisive factor on the effect of the composition of the high atmosphere of the planet. However, the country is expected to be very affected by climate change: especially the Colombian Andes (Perez et al. 2010). The eastern region of Colombia presents high vulnerability to the effects of climate change due to its high diversity of fauna and flora, potential direct impact on agricultural activities and the pressure on water resources.

Almost no research has been carried out focusing on the predicted changes on climate in Colombia for the next decades, especially on the eastern region. Only studies on related fields have been performed for other areas; Ruiz et al. (2008) analyzed the past change of climate during the last decades in a mountain basin on the west flank of the Colombian andean central mountain range, Nakaegawa and Vergara (2010) studied river discharge in the north of Colombia using direct output from a GCM as well as Ospina-Noreña et al. (2017), but there is no research for the east side and no regional downscaling approach have been carried out to determine a more accurate representation of the future climate in a specific region. With reference to the above factors and considering the great lack of detailed climate studies about Colombia, a research work is necessary to determine on a regional scale the possible change of climate variables such as precipitation, temperature, and relative humidity in Colombia for future decades. Additionally, this data must be compared against a reference period of historical records to comprehend the magnitude of the future climate change in the region and its potential impact.

\section{Study area}

The eastern side of Colombia borders Venezuela. It is characterized by different geographical and climate characteristics with a range of medium temperature from 12 to $34{ }^{\circ} \mathrm{C}$. The Amazon Rainforest is located in the southernmost part; the extensive valleys and Andean Mountains are found in the middle-east region of the country; and coastal plains to the high north. The areas analyzed in this study comprises 4 macro water districts located at the eastern and middle side of Colombia: each area presenting different geographic and climate conditions. These two regions lie between $74^{\circ} 56^{\prime} 13^{\prime \prime}$ and $66^{\circ} 82^{\prime} 29^{\prime \prime}$ west longitude, and between $12^{\circ} 24^{\prime} 40^{\prime \prime}$ north and $2^{\circ} 18^{\prime}$ $225^{\prime \prime}$ south latitudes. These specific regions are shown in the Fig. 1 and were selected due to their variability of conditions and the sufficient availability of data for the analysis. Colombia is located in tropical South America, which is dominated by the Amazon Rainforest. Precipitation throughout the country is highly influenced by the Inter Tropical Convergence Zone-ITCZ; however, the climate is also conditioned by local particularities like those caused by mountain barriers to the atmospheric circulation.

\section{Materials and methods \\ Datasets \\ Observed data}

The observed daily data of precipitation, maximum temperature (Tmax), minimum temperature (Tmin), and relative humidity $(\mathrm{RH})$ was collected from 153 hydrometeorological stations along the studied regions. A bigger amount of data was supplied by the Institute of Hydrology, Meteorology and Environmental Studies of Colombia (IDEAM) but only datasets with less than $30 \%$ of missing values for the time range of 1980-2015 were considered, complying with the minimum extension of records of 30 years, recommended by the World Meteorological Organization (WMO 2017), to obtain reliable statistics.

\section{Reanalysis data}

The daily mean atmospheric variables were obtained from the National Centre for Environmental Prediction 


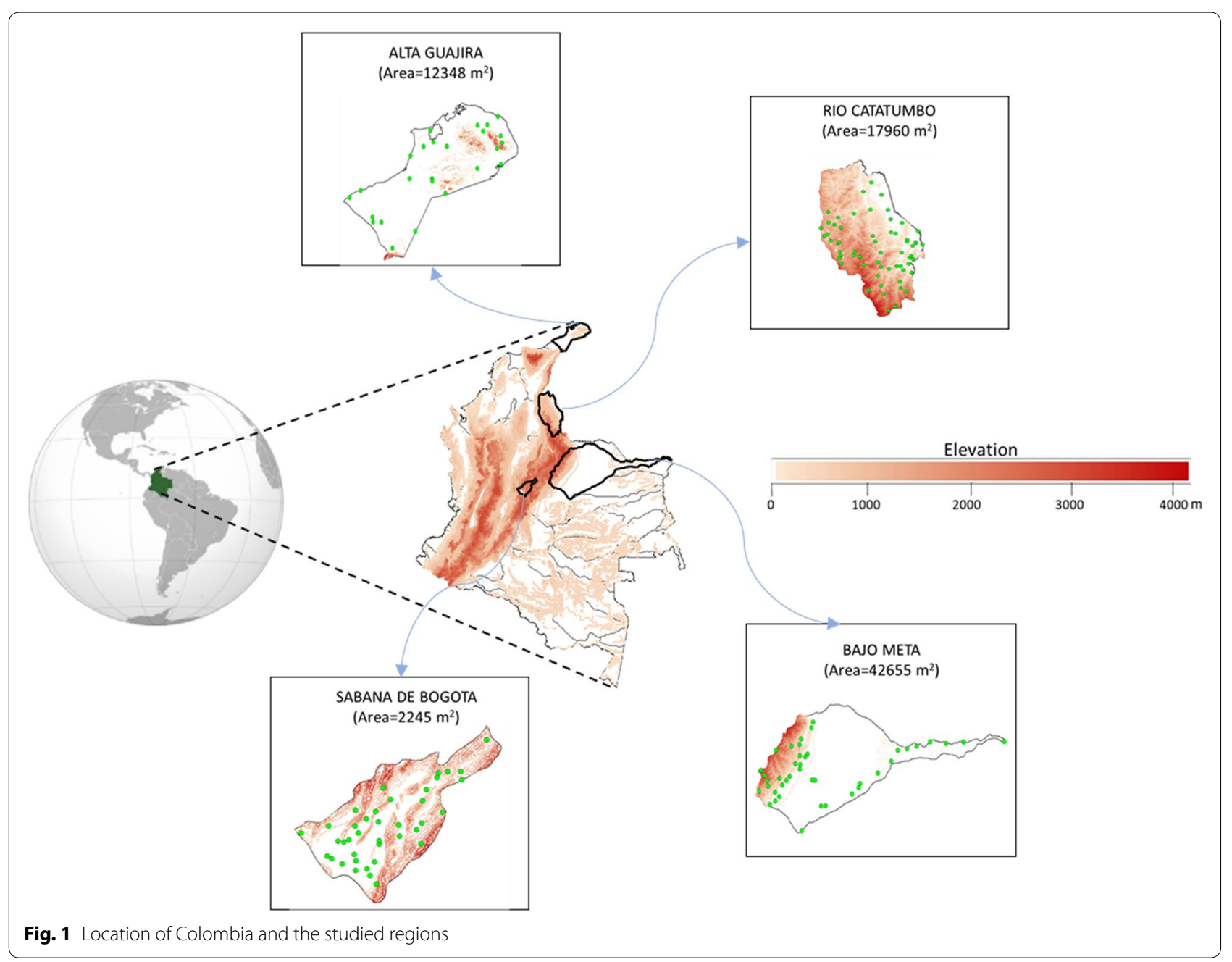

(NCEP-DOE 2) reanalysis dataset for the period from January 1980 to December 2015. The data has a resolution of $2.5^{\circ}$ latitude $\times 2.5^{\circ}$ longitude global grid and seventeen constant pressure levels in the vertical.

\section{GCM data}

The selection of the GCM's is made on the basis of literature review and availability of data. In a previous study, Bonilla-Ovallos and Mesa Sánchez (2017) evaluated the performance of the simulations of Global Climate Models from the CMIP5-project compared with local observations, the two GCM used in this study showed a good performance in this analysis. The GCMs selected for this study are CanESM2 $\left(2.79^{\circ}\right.$ latitude $\times 2.81^{\circ}$ longitude) and IPSL-CM5A-MR (1.26 latitude $\times 2.5^{\circ}$ longitude). CanESM2 is developed by Canadian Centre for Climate Modelling and Analysis, whereas IPSL-CM5AMR by The Institut Pierre Simon Laplace, France, respectively. The future Long-Term scenarios considered in this study are the Representative Concentration
Pathways (RCPs) RCP2.6 and RCP8.5 representing two different possible future emission trajectories and radiative forcings. The RCP8.5 combines assumptions about high population and relatively slow income growth with modest rates of technological change and energy intensity improvements, leading in the long term to high energy demand and GHG emissions in the absence of climate change policies. RCP8.5 thus corresponds to the pathway with the highest greenhouse gas emissions (Riahi 2011). The RCP 4.5 represents a scenario with lower concentration in the atmosphere of $\mathrm{CO}_{2}$ than RCP 8.5, here the emissions peak around midcentury at around 50\% higher than 2000 levels and then decline rapidly over 30 years. It is important to notice that concentration of $\mathrm{CO}_{2}$ continues to increase even after emissions slow and then drop. Carbon dioxide accumulates in the atmosphere and stays there for decades.

The predictor variables are available and obtained for the period 1980-2005 for historical data, and the period 
2021-2100 was used for the future projections of both models (van Vuuren et al. 2011).

\section{Statistical Downscaling Model (SDSM)}

The Statistical Downscaling Model was developed by Wilby et al. (2002) as a tool for statistical downscaling method. There are many studies which have used SDMS in climate change impact assessments (Rajabi and Shabanlou 2013). The model uses a combination of stochastic weather generator (SWG) and multiple linear regression (MLR). The MLR establishes a statistical relationship between GCM predictor variables and local-scale predictand variables to produce regression parameters. These calibrated regression parameters are further used with NCEP and GCM predictor variables in SWG to simulate daily time series producing a better correlation with the observed predictand's time series.

In SDSM, there are three kinds of sub-modelsmonthly, seasonal and annual sub-models-that comprise the statistical/empirical relationship between the regional-scale variables (temperature and precipitation) and large-scale variables (Hussain et al. 2017). There are also two options within sub-models: conditional and unconditional sub-models. The conditional sub-models are used for the parameters that are dependent on the occurrence of other climate parameters, i.e. precipitation, evaporation, etc., while the unconditional models are used for independent climate parameters, i.e. temperature.

\section{Screening of predictors}

The direct relationship between predicted variables and large-scale predictors as independent variables is considered to define a multiple linear regression model. The screening of predictors is an essential step of statistical downscaling with SDSM (Wilby et al. 2002). For this, a correlation analysis was applied between predictands (precipitation, Tmax, Tmin, and $\mathrm{RH}$ ) and daily data of 21 predictors based on explained variance, correlation coefficient, and the $\mathrm{p}$ value. In this way the best correlation between individual predictors and predictand was found. The predictor with the highest correlation was selected as main predictor, also called superpredictor, setting the significance level of $\mathrm{P}<0.05$ as default value. After selecting the main predictor, a second and third predictors were also selected based on highest correlation and explained variance. Similar studies have used the method performed in the current study for the selection of the appropriate predictors (Saddique et al. 2019; Khan and Coulibaly 2006; Gulacha and Mulungu 2017).

The correlation found between the predictand and predictors in the case of precipitation was low, this was

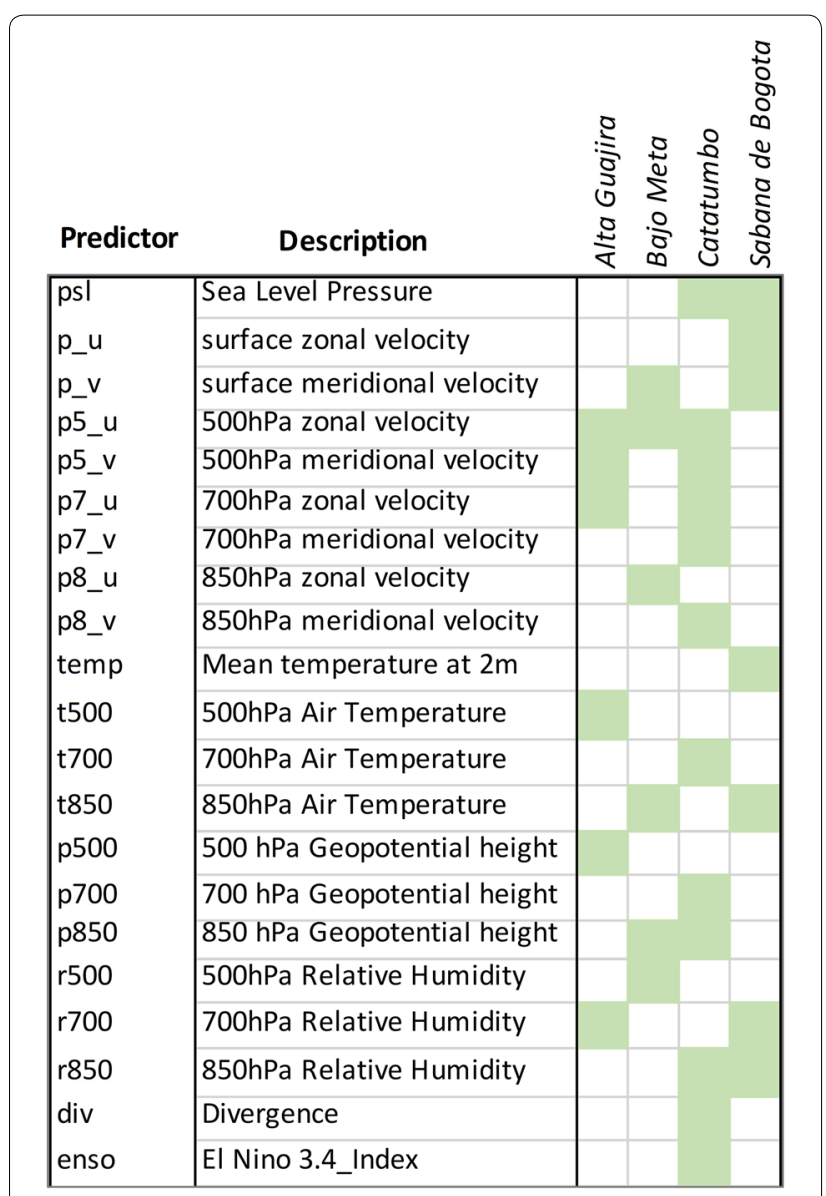

Fig. 2 Most used predictors for SDSM using inputs from NCEP-DOE 2

expected considering other similar studies and the difficulties for downscaling with high accuracy daily precipitation (Hashmi et al. 2011; Huang et al. 2011; Meaurio et al. 2017). For regions at high elevation (Sabana de Bogota and Rio Catatumbo) superpredictor were found at $500 \mathrm{hPa}$ while for regions at low elevations (Alta Guajira and Bajo Meta) superpredictors were found at surface level and $850 \mathrm{hPa}$. Figure 2 summarizes the results of the most used predictors due to its better correlation with the downscaled variables for each evaluated region.

\section{Model performance}

During the validation period, the four different variables were simulated using the NCEP data, as well as the historical data from both GCM datasets (CanESM2, IPSL-CM5A-MR) and compared with observations in order to evaluate the model performance in the different cases. For this, the correlation coefficient (R), root 
Table 1 Performance of model for daily time series of $\mathrm{Tmax}$, $\mathrm{Tmin}$, $\mathrm{RH}$, and precipitation during the calibration period (1981-2000)

\begin{tabular}{|c|c|c|c|c|c|c|c|c|}
\hline & \multicolumn{2}{|c|}{ Tmax } & \multicolumn{2}{|l|}{ Tmin } & \multicolumn{2}{|c|}{ Rel. Humidity } & \multicolumn{2}{|c|}{ Precipitation } \\
\hline & $\mathbf{R}$ & RMSE & $\mathbf{R}$ & RMSE & $\mathbf{R}$ & RMSE & $\mathbf{R}$ & RMSE \\
\hline \multicolumn{9}{|c|}{ Alta Guajira } \\
\hline NCEP & 0.78 & 0.8 & 0.72 & 0.73 & 0.65 & 11.87 & 0.27 & 6.23 \\
\hline \multicolumn{9}{|c|}{ Bajo Meta } \\
\hline NCEP & 0.66 & 1.14 & 0.61 & 0.82 & 0.54 & 5.13 & 0.25 & 34.61 \\
\hline \multicolumn{9}{|c|}{ Rio Catatubo } \\
\hline NCEP & 0.82 & 1.91 & 0.77 & 1.43 & 0.65 & 21.23 & 0.35 & 59.23 \\
\hline \multicolumn{9}{|c|}{ Sabana de Bogota } \\
\hline NCEP & 0.8 & 0.64 & 0.81 & 0.52 & 0.74 & 11.19 & 0.31 & 13.12 \\
\hline
\end{tabular}

mean square error (RMSE) and normalized root mean square error (NRMSE) were used.

$$
\begin{aligned}
& R=\frac{4 \sum_{i=1}^{N}\left(P_{i}-\bar{P}\right) \cdot\left(O_{i}-\overline{\mathrm{O}}\right)}{\sqrt{\sum_{i=1}^{N}\left(P_{i}-\bar{P}\right)^{2}} \cdot \sqrt{\sum_{i=1}^{N}\left(O_{i}-\overline{\mathrm{O}}\right)^{2}}} \\
& R M S E=\frac{\sqrt{\sum_{i=1}^{N}\left(O_{i}-P_{i}\right)^{2}}}{\sqrt{N}} \\
& \text { NRMSE }=\frac{R M S E}{\overline{\mathrm{O}}}
\end{aligned}
$$

where $\mathrm{O}_{\mathrm{i}}$ and $\mathrm{P}_{\mathrm{i}}$ are the observed and modeled values, respectively, $\overline{\mathrm{O}}$ and $\overline{\mathrm{P}}$ are the means of the observed and modeled values, respectively, and $\mathrm{N}$ is the number of data points. A Taylor diagram (Taylor 2001) is used as well to quantify the statistical relationship between observed and modeled data for each of the analyzed regions and scenarios. In this diagram, the relationship is represented by the correlation coefficient (R), the standard deviation $(\sigma)$ and the centered root mean square difference (RMS), an independent diagram is shown for each parameter.

\section{Results}

\section{Model calibration and validation}

Based on the available datasets of observations, two daily data sets for the periods 1980-1999 and 2000-2015, were selected for the model calibration and validation, respectively. This for every station of the studied regions. SDSM is calibrated using observed station scale data (Tmax, Tmin, Precipitation and Relative Humidity) and sets of observed predictors, i.e., NCEP reanalysis datasets. A monthly sub-model was set for the process of calibration, which derives 12 different regression equations, one for each month, and the optimization of the best fit is performed by the ordinary Least Squares Method.

With the calibrated model for the period of 1980-1999, 20 daily ensembles for every variable were simulated for the periods of calibration and validation. The mean value of these 20 ensembles was compared with the observed data. The correlation coefficient and root mean square error were used as performance indicators during the calibration and validation process. Table 1 and the Taylor diagrams in Fig. 4 show the general model's performance during the calibration and validation periods. Here, the given $R$ and RMSE values are taken as an average value for the group of stations that belong to each region. Some of the studied regions include stations in a wide range of elevation. Such is the case, for example, of the region Bajo Meta, with stations below $500 \mathrm{~m}$ and others above $3500 \mathrm{~m}$ of elevation. These groups of stations represent results in different ranges for each modeled variable. Figure 3 presents an example of the validation results concluded over an average result for a group of stations located in the range of $500 \mathrm{~m}$ of elevation for each region.

The Taylor diagrams provided in the Fig. 4 are a brief statistical summary of standard deviation, correlation coefficient and root mean square difference according to the results of SDSM for the downscaling of daily maximum and minimum temperature, relative humidity and precipitation.

\section{Climatic scenarios generation}

Data from the selected GCM models was used into the developed and calibrated SDSM model to simulate daily values of precipitation, Tmax, Tmin and relative humidity for two future periods: 2021-2050 and 2071-2100, this for both GCM and both Representative Concentration Pathways. Future changes in the variables were calculated by comparing them to a baseline period from 1981 to 2010. In the Figs. 5 and 6 a comparison of the 


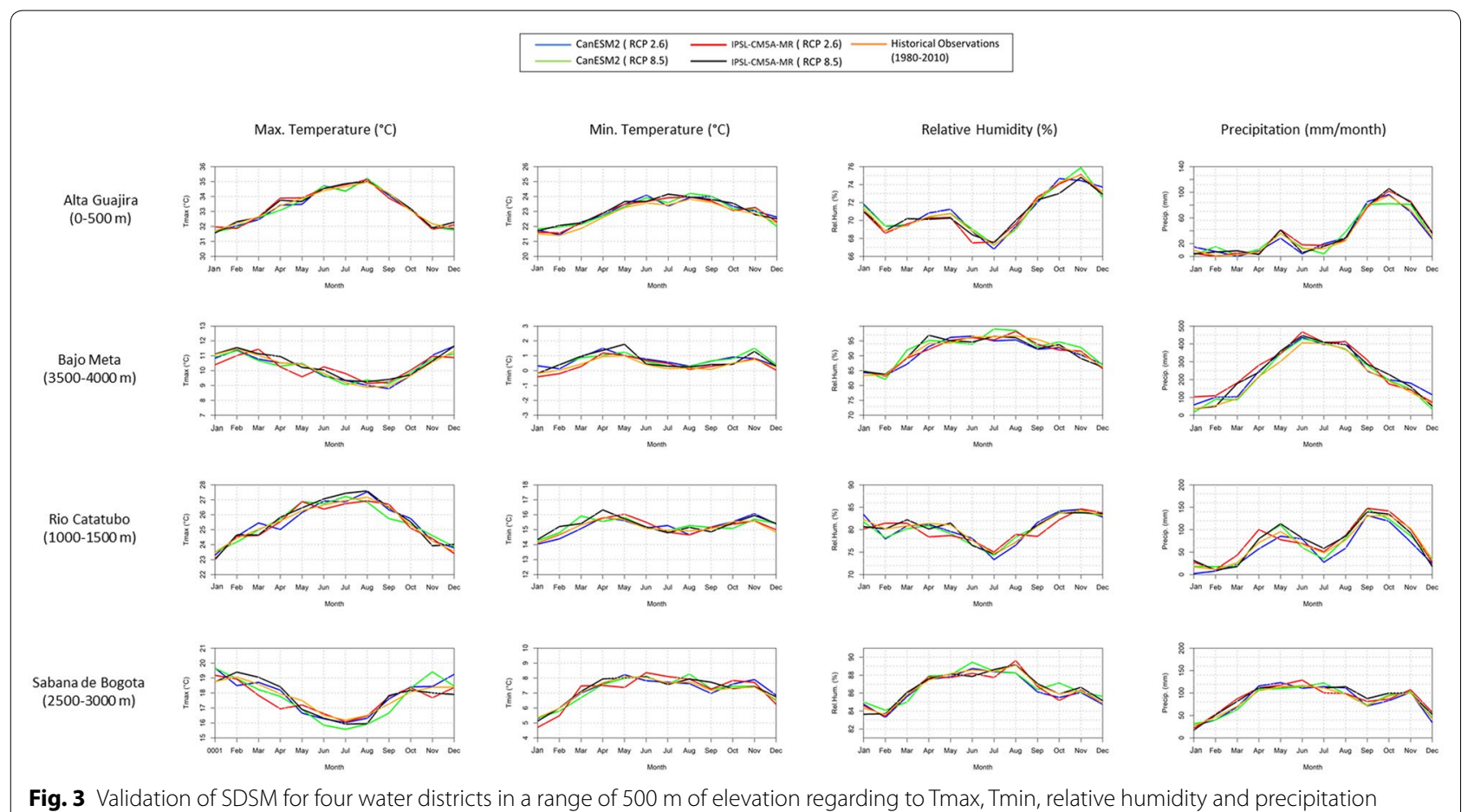

Fig. 3 Validation of SDSM for four water districts in a range of $500 \mathrm{~m}$ of elevation regarding to Tmax, Tmin, relative humidity and precipitation

simulated results is made with the baseline period of observations in 1981-2010. Using the mean value for the 30 -year period, it is possible to calculate the relative increment or decrease for each projected variable in the future compared to the reference period of 1981-2010; these values can be observed in the Table 2 .

\section{Discussion}

The results presented in Table 2 show an increase of both maximum and minimum temperature over the next decades as well as a decrease in relative humidity with a slight change of precipitation which will most likely decrease for most of the considered stations-especially in the last decades of the XXI century. In contrast to the case of temperature, difficulties to perform accurately a downscaling of daily precipitation agrees with the results of other studies (Huang et al. 2011; Nguyen et al. 2006; i.a., González-Rojí et al. 2019; Saraf and Regulwar 2016; Ahmadi et al. 2014; Saddique et al. 2019; Hussain et al. 2017; Cavazos and Hewitson 2005; Fiseha et al. 2012; Osma et al. 2015), also in these studies a low correlation in a regional scale between daily precipitation and different set of predictors was found, this creates a difficulty to adjust the model and calibrate it more accurately. That can be seen in this study in the Figs. 3 and 4. This partial inability of the statistical model of reproducing daily precipitation is also due to regional physicalgeographic factors like interactions of atmospheric flow with topography, combined with land-use and land-cover changes that play a role in the formation of precipitation and show high variability in inter-annual basis. This confirms the high sensitivity of mountainous regions and the complex climate processes at play, which have been found as well in other studies (Gulacha and Mulungu 2017; Sigdel and Ma 2015; Mahmood and Babel 2013).

The projected increase in temperature as shown by the CanESM2 model, is slightly higher than the IPSLCM5A-MR model, both for maximum and minimum temperature. Regarding the change of precipitation, Rio Catatubo, Bajo Meta and Alta Guajira show a general decrease over their area while Sabana de Bogota was the only region that presents an increase. However, it must be considered that these results are a mean average from all the stations located in each region and it is given in these terms in order to have a general overview of the different climate variables on each region on the future caused by different scenarios of greenhouse emissions and climate change. The projected values may relatively differ for each station with regards to the elevation where is located and regional physical-geographic factors such as orography.

In terms of geographic perspective, the greatest increase in maximum and minimum temperature is observed in Bajo Meta and Sabana de Bogota (which are mountainous regions), while the lowest increase is observed in the Alta Guajira region (which is located 


\begin{tabular}{|r|c|c|c|c|}
\cline { 2 - 5 } \multicolumn{1}{c|}{} & Precip. & R.H. & Tmax & Tmin \\
\hline CanESM2 (RCP 2.6) & $\bullet$ & $\boldsymbol{\Delta}$ & $\mathbf{\square}$ & \\
\hline CanESM2 (RCP 8.5) & $\bullet$ & $\boldsymbol{\Delta}$ & $\square$ & \\
\hline IPSL-CM5A-MR (RCP 2.6) & $\bullet$ & $\boldsymbol{\Delta}$ & $\mathbf{\square}$ & \\
\hline IPSL-CM5A-MR (RCP 8.5) & $\bullet$ & - & & \\
\hline
\end{tabular}

a

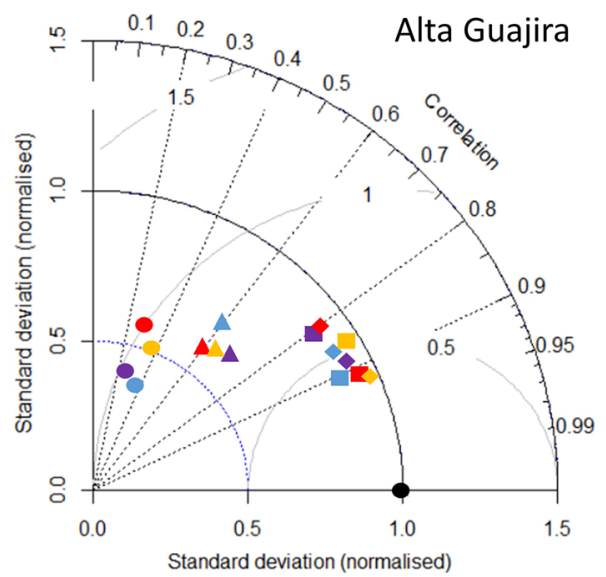

c

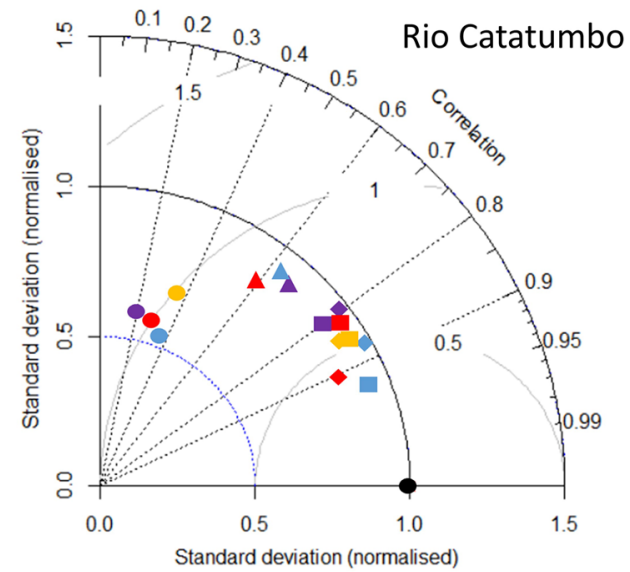

b

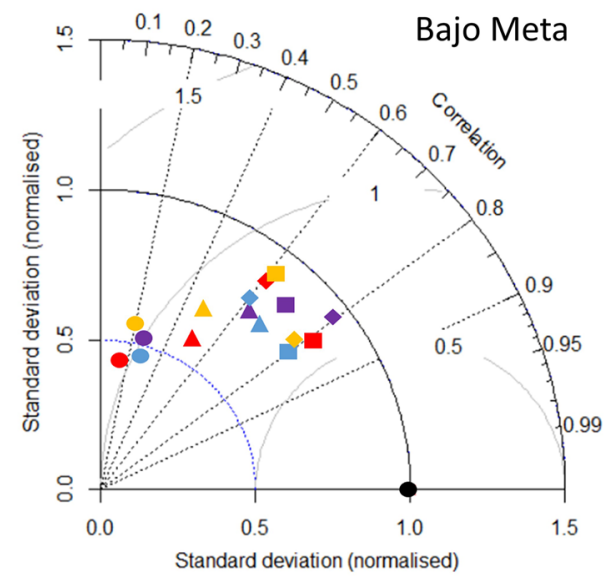

d

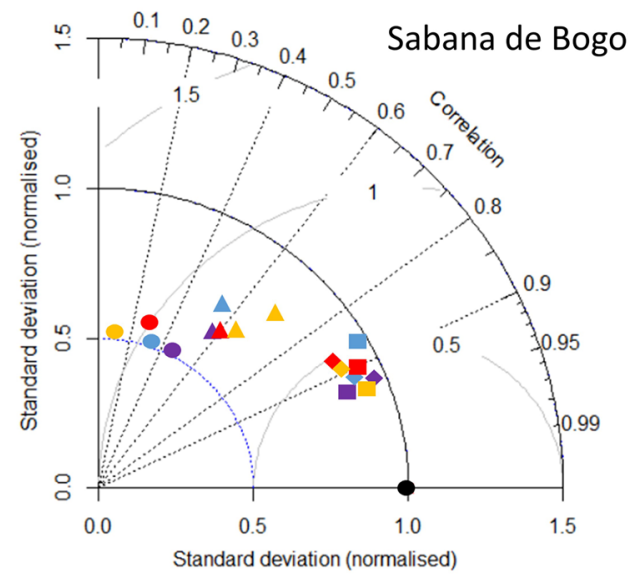

Fig. 4 Taylor diagrams for two GCMs and two scenarios during SDSM validation for all parameters in a Alta Guajira, b Bajo Meta, c Rio Catatumbo, d Sabana de Bogota

at the northern coast). In general, it is observed from the output of various scenarios that the mountainous stations with drier climate show a higher probability of rising temperatures during the coming decades. The projections obtained with the Representative Concentration Pathway RCP 8.5 were expected to show the highest increase in temperature compared with those made using the RCP 2.6. Since the first mentioned represents the worst-case scenario of greenhouse gas emissions for the first decades of XXI century, and this was in fact the result that was observed at most of the stations. This can be seen in the examples shown in Fig. 5; however, the maximum temperature that was projected using the model CanESM2 RCP2.6 is for some stations higher than the one obtained with RCP 8.5 with the model IPSL-CM5A-MR. This might indicate (in some degree) inconsistency or instability in the global projections of the models in some locations.

Considering the two different modeled periods and the characteristics of the different Representative Concentration Pathways (RCPs) the changes obtained for the 

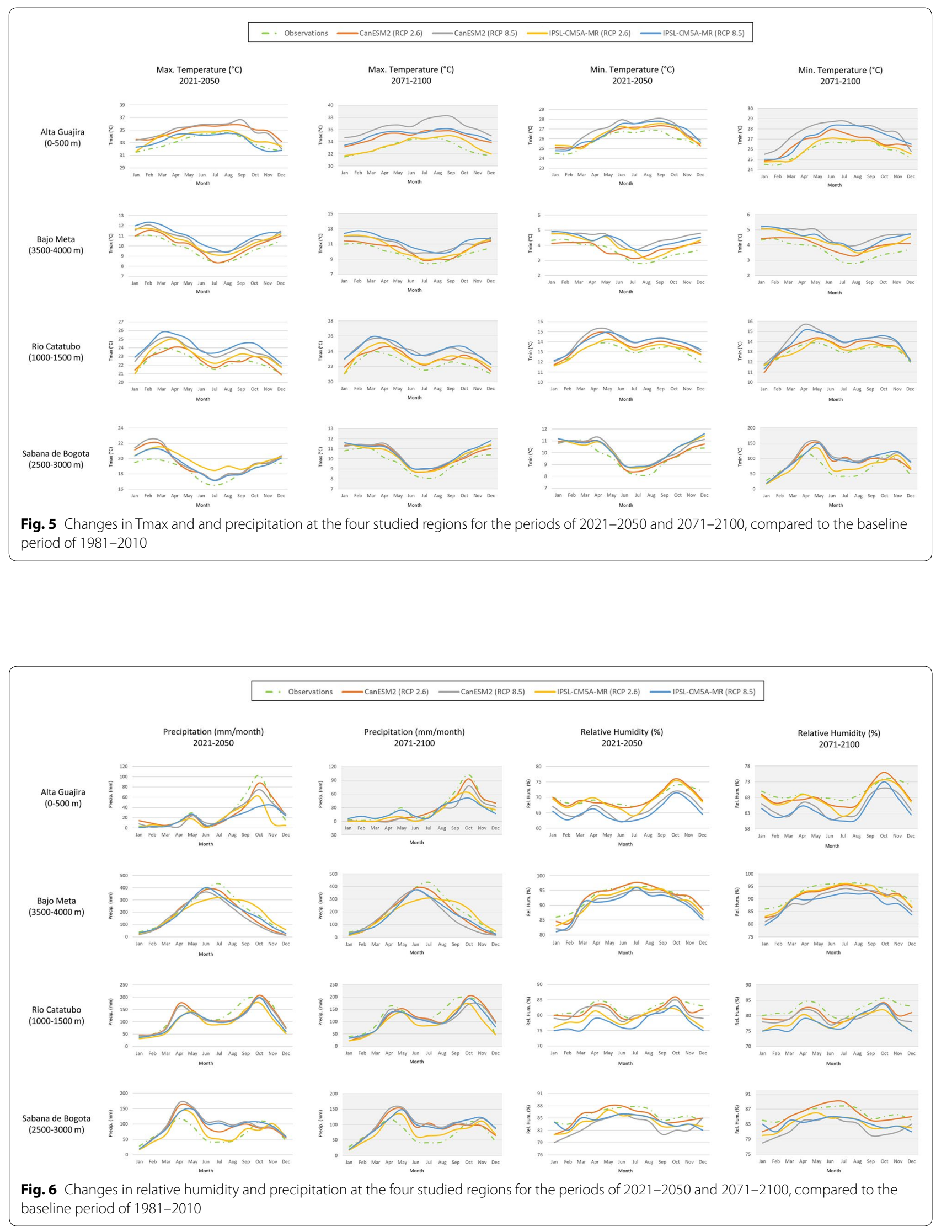
Table 2 Reductions and/or increases in ${ }^{\circ} \mathrm{C}$ for temperature and in $\%$ for relative humidity and precipitation for two future periods compared to the reference period of 1981-2010

\begin{tabular}{|c|c|c|c|c|c|c|c|c|}
\hline & $2020-2050$ & $2070-2100$ & $2020-2050$ & $2070-2100$ & $2020-2050$ & $2070-2100$ & $2020-2050$ & $2070-2100$ \\
\hline \multicolumn{9}{|l|}{ Alta Guajira } \\
\hline CanESM2 (RCP 2.6) & 0.3 & 0.5 & 0.6 & 0.7 & -2.3 & -3.1 & 0.5 & -3 \\
\hline CanESM2 (RCP 8.5) & 0.7 & 1 & 1.3 & 1.5 & -6.3 & -7.1 & -0.4 & -1.6 \\
\hline IPSL-CM5A-MR (RCP 2.6) & 0.4 & 0.8 & 0.9 & 1.1 & -3.5 & -4.3 & 0.1 & -4.1 \\
\hline IPSL-CM5A-MR (RCP 8.5) & 0.8 & 1.4 & 1.1 & 1.3 & -2.9 & -3.7 & -0.4 & -1.9 \\
\hline \multicolumn{9}{|l|}{ Bajo Meta } \\
\hline CanESM2 (RCP 2.6) & 1.1 & 1.8 & 1.1 & 2.2 & -1.5 & -2.3 & -2.3 & -5 \\
\hline CanESM2 (RCP 8.5) & 1.5 & 2.6 & 2.2 & 3.3 & -5.5 & -6.3 & -3.4 & -4.6 \\
\hline IPSL-CM5A-MR (RCP 2.6) & 0.9 & 1.4 & 1.4 & 2.5 & -2.7 & -3.5 & -1.2 & -6.1 \\
\hline IPSL-CM5A-MR (RCP 8.5) & 1.2 & 2.7 & 2 & 3.1 & -2.1 & -2.9 & -3.6 & -8.9 \\
\hline \multicolumn{9}{|l|}{ Rio Catatubo } \\
\hline CanESM2 (RCP 2.6) & 1.9 & 3.2 & 0.3 & 2 & -1.3 & -2.4 & -2 & -4 \\
\hline CanESM2 (RCP 8.5) & 2.7 & 3.2 & 0.7 & 2.5 & -5.3 & -6.4 & -1.6 & -3.6 \\
\hline IPSL-CM5A-MR (RCP 2.6) & 2.2 & 2.8 & -0.2 & 0.9 & -2.5 & -3.6 & -3.1 & -5.1 \\
\hline IPSL-CM5A-MR (RCP 8.5) & 3.2 & 3.5 & 0.5 & 1.6 & -1.9 & -3 & -5.9 & -7.9 \\
\hline \multicolumn{9}{|l|}{ Sabana de Bogota } \\
\hline CanESM2 (RCP 2.6) & 2.6 & 2.9 & 1 & 1.7 & -3.1 & -5.2 & 1 & 2 \\
\hline CanESM2 (RCP 8.5) & 3 & 3.6 & 2.1 & 2.8 & -7.1 & -9.2 & 2.4 & 3.4 \\
\hline IPSL-CM5A-MR (RCP 2.6) & 1.7 & 2.2 & 1.3 & 2 & -4.3 & -6.4 & -0.1 & 0.9 \\
\hline IPSL-CM5A-MR (RCP 8.5) & 2.1 & 2.7 & 1.9 & 2.6 & -3.7 & -5.8 & 1.9 & 3.2 \\
\hline
\end{tabular}

period of 2071-2100 are, as expected, bigger than for the period 2021-2050 when compared to the baseline period of observations (1981-2010). A more detailed analysis of the spatial distribution of the projected climate changes shows that groups of station located at low elevations (below $1000 \mathrm{~m}$ ) present a more spatially uniform results than those at higher elevations. This was the case for three of the four regions. More uniformity is also found for the period of 2071-2100 than for 2021-2050.

An important inference of the performed approach and as concluded in other studies (Gebrechorkos and Bernhofer 2019), the selection of the best fit predictors for a given predictand at a particular location, represents the key part of the modelling process and enables to accurately reproduce and predict the observed station data. The predictors that showed the best correlations with precipitation as predictand are related mostly with wind speed, geopotential, as well as high and relative humidity. This agrees with other studies using statistical downscaling methods (e.g., Hussain et al. 2017; Saraf and Regulwar 2016). A bias correction was not applied to the global climate data because it was found that bias correction methods might impair the advantages of circulation models by altering spatiotemporal field consistency, relations among variables, and by violating conservation principles. This might additionally neglect feedback mechanisms (Ehret et al. 2012); moreover, the resulting correlation coefficients found in the calibration and validation procedure were significant to assume a direct predictor-predictand relationship.

Since the projected scenarios for precipitation don't show a general tendency over the four studied regions, an alternative method is suggested for daily precipitation regional downscaling in order to compare the results or find higher accuracy e.g. generalized linear models or the use of neural network approach. In the same way, it is recommended that the results from this study be compared with other regional climate modeled datasets such as CORDEX in order to validate or complement the analysis of the results. The use of a dynamical downscaling method could provide more accurate results as well but this approach demands much more intensive computational resources and require large volumes of data which were not available for the studied regions.

For a more detailed analysis of the predictors and in order to identify potential better correlations with the historical records, the lagging of daily predictor variables could be applied as well as suggested for some authors (e.g., Harpham and Wilby 2005; Crawford et al. 2007) with the purpose of revealing hidden direct relationships between predictand and predictors; this is because predictors from distant grid-boxes may also influence the local climate in distinct time. 


\section{Conclusions}

The results obtained during the process of calibration and validation define the model developed by SDSM as efficient in the downscaling of maximum/minimum temperature and relative humidity over the studied regions. With regards to precipitation the model shows a lower performance, which is not unusual compared to other statistical downscaling studies.

The GCMs used in this study show a projected increase of both maximum and minimum temperature over the next decades on the studied regions as well as a decrease in relative humidity with a slight change of precipitation with a most likely tendency to decrease for most of the considered stations, especially in the last decades of the XXI century.

The distribution density of stations into the studied regions (especially the Alta Guajira and Bajo Meta regions) is low when compared with other regions of the country. Even though these regions have importance regarding the agricultural and energy sector, there is still a higher attention on surveilling climate parameters in more urban areas in Colombia. The low amount of climate records and particularly those for temperature, relative humidity, radiation, and wind speed make it difficult to conduct a more proper technical climate analysis and thus creates higher uncertainties when calibrating climate models with the historical records for these regions.

Performing this study over four different regions offers a good opportunity to evaluate the performance of the tool SDSM over different geographic and climate conditions. Along the same lines, the results of the projections offer good information for the evaluation of possible future-case scenarios and decisions-making management. These results are useful for development planners, decision makers, as well as other stakeholders when planning and implementing appropriate management strategies regarding to adaptation and mitigation of climate change for these regions.

\begin{abstract}
Abbreviations
SDSM: Statistical Downscaling Model; GCMs: Global Climate Models; Tmax: maximum temperature; Tmin: minimum temperature; $\mathrm{RH}$ : relative humidity; $\mathrm{R}$ : correlation coefficient; RMSE: root mean square error; NRMSE: normalized root mean square error; RMS: root mean square difference; NCEP: National Centre for Environmental Prediction; IPCC: Intergovernmental Panel on Climate Change; ITCZ: Inter Tropical Convergence Zone; MJO: Madden-Julian oscillation; IDEAM: Institute of Hydrology, Meteorology and Environmental Studies of Colombia; RCM: Regional Climate Models; WMO: World Meteorological Organization; RCP: Representative Concentration Pathway; GHG: greenhouse gases; MLR: multiple linear regression; NCEP: National Center for Environmental Prediction; SWG: stochastic weather generator.
\end{abstract}

\section{Acknowledgements}

Special acknowledgements to the Institute of Hydrology and Meteorology of the Technical University Dresden for the support during this research project. We want to thank IDEAM in Colombia for providing the available historical records in the area and to the German Academic Exchange Service (DAAD) for providing the financial support for Mr. Molina's studies.

\section{Authors' contributions}

OM obtained, analyzed and interpreted the climate data and performed the modeling-task. CB contributed with co-planning, guidance and supervising the project and the manuscript. Both authors read and approved the final manuscript.

\section{Funding}

The DAAD (German Academic Exchange Service) is the provider of the scholarship in which this research project took place. Funding for publication is provided by the Publication Fund of the TU Dresden (Grant Number IN-1502335).

Availability of data and materials

Not applicable.

Ethics approval and consent to participate

Not applicable.

Consent for publication

Not applicable.

\section{Competing interests}

The authors declare that they have no competing interests.

Received: 8 August 2019 Accepted: 11 November 2019

Published online: 18 November 2019

\section{References}

Ahmadi A, Moridi A, Lafdani EK, Kianpisheh G (2014) Assessment of climate change impacts on rainfall using large scale climate variables and downscaling models-a case study. J Earth Syst Sci 123:1603-1618. https://doi. org/10.1007/s12040-014-0497-x

Bonilla-Ovallos CA, Mesa Sánchez OJ (2017) Validación de la precipitación estimada por modelos climáticos acoplados del proyecto de intercomparación CMIP5 en Colombia. Revista De La Academia Colombiana De Ciencias Exactas, Físicas Y Naturales 41(158):107-118. https://doi. org/10.18257/raccefyn.427

Cavazos T, Hewitson B (2005) Performance of NCEP-NCAR reanalysis variables in statistical downscaling of daily precipitation. Clim Res 28:95-107

Crawford T, Betts NL, Favis-Mortlock D (2007) GCM grid-box choice and predictor selection associated with statistical downscaling of daily precipitation over Northern Ireland. Clim Res 34:145

Ehret U, Zehe E, Wulfmeyer V (2012) Should we apply bias correction to global and regional climate model data? Hydrol Earth Syst Sci 16:3391-3404

Fiseha BM, Melesse A, Romano E, Volpi E, Fiori A (2012) Statistical downscaling of precipitation and temperature for the Upper Tiber Basin in Central Italy. Int J Water Sci 1(3):1-14

Gebrechorkos SH, Bernhofer C, Hülsmann S (2019) Regional climate projections for impact assessment studies in East Africa. Environ Res Lett 14:04403. https://doi.org/10.1088/1748-9326/ab055a

González-Rojí SJ, Wilby RL, Sáenz J, Ibarra-Berastegi G (2019) Harmonized evaluation of daily precipitation downscaled using SDSM and WRF + WRFDA models over the Iberian Peninsula. Clim Dyn 53:1413-1433. https://doi. org/10.1007/s00382-019-04673-9

Gulacha MM, Mulungu DMM (2017) Generation of climate change scenarios for precipitation and temperature at local scales using SDSM in WamiRuvu River basin Tanzania. Phys Chem Earth 100:62-72. https://doi. org/10.1016/j.pce.2016.10.003

Harpham C, Wilby RL (2005) Multi-site downscaling of heavy daily precipitation occurrence and amounts. J Hydrol 312:235-255

Hashmi MZ, Shamseldin AY, Melville BW (2011) Comparison of SDSM and LARS-WG for simulation and downscaling of extreme precipitation events in a watershed. Stoch Environ Res Risk A 25(4):475-484. https:// doi.org/10.1007/s00477-010-0416-X

Huang J, Zhang J, Zhang Z, Xu C, Wang B, Yao J (2011) Estimation of future precipitation change in the Yangtze River basin by using statistical 
downscaling method. Stoch Environ Res Risk A. 25(6):781-792. https:// doi.org/10.1007/s00477-010-0441-9

Hussain M, Yusof KW, Mustafa MR, Mahmood R, Shaofeng J (2017) Projected changes in temperature and precipitation in Sarawak state of Malaysia for selected CMIP5 climate scenarios. Int J Sustain Dev Plan 12(8):1299-1311

IDEAM-Institute of Hydrology, Meteorology and Environmental Studies (2005) Atlas Climatico de Colombia. Imprenta Nacional de Colombia. ISBN 958-8067-14-6

Jones RG, Noguer M, Hassell DC, Hudson D, Wilson SS, Jenkins GJ, Mitchell JFB (2004) Generating high resolution climate change scenarios using PRECIS. UK Met Office Hadley Centre, p 40

Khan MS, Coulibaly P, Dibike Y (2006) Uncertainty analysis of statistical Downscaling methods. J Hydrol 319(1-4):357-382. https://doi.org/10.1016/j. jhydrol.2005.06.035

Mahmood R, Babel M (2013) Evaluation of SDSM developed by annual and monthly sub-models for downscaling temperature and precipitation in the Jhelum basin, Pakistan and India. Theor Appl Climatol 113:27-44

Meaurio M, Zabaleta A et al (2017) Assessing the hydrological response from an ensemble of CMIP5 climate projections in the transition zone of the Atlantic region (Bay of Biscay). J Hydrol 548:46-62. https://doi. org/10.1016/j.jhydrol.2017.02.029

Nakaegawa T, Vergara W (2010) First projection of climatological mean river discharges in the Magdalena River Basin, Colombia, in a changing climate during the 21st century. Hydrol Res Lett 4:50-54. https://doi.org/10.3178/ HRL. 4.50

Nguyen VTV, Nguyen TD, Gachon P (2006) On the linkage of large-scale climate variability with local characteristics of daily precipitation and temperature extremes: an evaluation of statistical downscaling methods. Advances in geosciences. Hydrological science (HS), vol 4. World Scientific Publishing Company, Singapore. https://doi.org/10.1142/97898 127072080001

Osma VC, Romá JEC, Martín MAP (2015) Modelling regional impacts of climate change on water resources: the Jucar basin, Spain. Hydrol Sci J 60:30-49

Ospina-Noreña J, Domínguez C, Vega-Rodríguez E, Darghan A, Rodríguez L (2017) Analysis of the water balance under regional scenarios of climate change for arid zones of Colombia. Atmósfera 30(1):63-76. https://doi. org/10.20937/ATM.2017.30.01.06

Perez C, Nicklin C, Dangles O, Vanek S, Sherwood S, Halloy S et al (2010) Climate change in the high Andes: implications and adaptation strategies for smallscale farmers. Int J Environ Cult Econ Soc Sustain Ann Rev. 6(5):71-88
Rajabi A, Shabanlou S (2013) The analysis of uncertainty of climate change by means of SDSM model case study: Kermanshah. World Appl Sci J 23:1392-1398

Riahi K, Rao S, Krey V, Cho C, Chirkov V, Fischer G, Kindermann G, Nakićenović N, Rafaj P (2011) RCP 8.5-A scenario of comparatively high greenhouse gas emissions. Clim Change 109:33-57. https://doi.org/10.1007/s1058 4-011-0149-y

Ruiz D, Moreno HA, Gutiérrez ME, Zapata PA (2008) Changing climate and endangered high mountain ecosystems in Colombia. Sci Total Environ 398:122-132. https://doi.org/10.1016/j.scitotenv.2008.02.038

Saddique N, Bernhofer C, Kronenberg R et al (2019) Downscaling of CMIP5 models output by using statistical models in a data scarce mountain environment (Mangla Dam Watershed), Northern Pakistan. Asia-Pacific J Atmos Sci 55:719. https://doi.org/10.1007/s13143-019-00111-2

Saraf VR, Regulwar DG (2016) Assessment of climate change for precipitation and temperature using statistical downscaling methods in Upper Godavari River Basin, India. J Water Resour Prot 8:31-45

Sigdel M, Ma Y (2015) Evaluation of future precipitation scenario using statistical downscaling model over humid, subhumid, and arid region of Nepal — a case study. Theor Appl Climatol 123:453-460

Taylor KE (2001) Summarizing multiple aspects of model performance in a single diagram. J Geophys Res 106(D7):7183-7192. https://doi. org/10.1029/2000JD900719

van Vuuren DP et al (2011) The representative concentration pathways: an overview. Clim Change 109(1-2):5

Wilby RL, Wigley TML (2000) Precipitation predictors for downscaling: observed and general circulation model relationships. Int J Climatol 20:641-661

Wilby RL, Dawson CW, Barrow EM (2002) SDSM a decision support tool for the assessment of regional climate change impacts. Environ Model Softw 17(2):147-159

WMO (2017) WMO Guidelines on the Calculation of Climate Normals. Chairperson, Publications Board, WMO-No. 1203

\section{Publisher's Note}

Springer Nature remains neutral with regard to jurisdictional claims in published maps and institutional affiliations.

\section{Submit your manuscript to a SpringerOpen ${ }^{\circ}$ journal and benefit from:}

- Convenient online submission

- Rigorous peer review

- Open access: articles freely available online

- High visibility within the field

- Retaining the copyright to your article

Submit your next manuscript at $\boldsymbol{\nabla}$ springeropen.com 